\title{
Economic and Environmental Packaging Sustainability: A Case Study
}

\author{
Iván González-Boubeta (iD, Mar Fernández-Vázquez-Noguerol (iD, \\ Pablo Domínguez-Caamaño (D), José Carlos Prado-Prado(D \\ University of Vigo (Spain) \\ ivangonzalezboubeta@uvigo.es,marfernandezvarquez@wigo.es,padominguę@migo.es,jcprado@migo.es
}

Received: November 2017

Accepted: February 2018

\section{Abstract:}

Purpose: The aim of this paper is to analyze the suitability of the packaging strategy of an important Spanish agro-food company, regarding to economic and environmental sustainability.

Design/methodology/approach: Three different types of packaging are analyzed to obtain a diagnostic of the initial situation. In this process, cost and carbon footprint are calculated in order to measure the economic and environmental impacts, respectively. Then, a new packaging allocation logic is proposed with the aim of improving both aspects.

Findings: The results show that the carbon footprint is strongly and positively affected by the cost reduction, showing the viability of a win-win relationship between both aspects.

Research limitations/implications: The strength of this win-win relationship may be conditioned by the input values considered in this case study. Conversion factors used to calculate carbon footprint vary a lot among researchers, showing the need of standardization in this topic.

Practical implications: Since the existence of a positive relationship between economic and environmental sustainability has been demonstrated, organizations should find this kind of situations in themselves to satisfy their own stakeholders.

Originality/value: This article shows the potential of unite waste elimination with eco-friendly activities with the aim of increasing the competitiveness of companies. This paper also contributes to the knowledge of economic and environmental sustainability and reinforces theoretical aspects, paving the way for further research on these topics.

Keywords: sustainability, reusable packaging, disposable packaging, distribution, transport

\section{Introduction}

In the world of today, competitiveness and turbulences in markets are a reality for almost all sectors. This aspect, together with the society's growing concern for climate change and the world of tomorrow, has generated a great interest in the concept of sustainability. According to the World Commission on Environment and Development, the main idea of sustainability consists in seeking "the needs and aspirations of the present without compromising the ability to meet those of the future" (World Commission on Environment and Development, 1987: page 39). In this framework, the "triple bottom line" is a widely recognized approach proposed by Elkington (1997), which considers the existence of the economic, environmental and social dimensions. However, despite the fact that these three pillars are easily identifiable, the economic and 
environmental dimensions are the most studied in sustainable supply chain management (Bendul, Rosca \& Pivovarova, 2017), while the social aspect is usually left aside.

Related to sustainability, the positive and negative environmental impacts of logistics activities are frequently discussed in literature. However, the study of environmental issues is often isolated from the economic aspect, which conditions the implementation of eco-friendly activities. In the food industry, one of the areas with a higher impact on the environment, there is no correspondence between scientific interest and the interests shown by companies in the environmental impact generated by this sector (Johansson \& Hellström, 2007). Publications on this topic have been growing in the past years, but according to Piotrowicz and Cuthbertson (2015) economic metrics dominate in practice, whereas environmental measures only seem to be considered when they are backed up by a legal obligation. One of the reasons for this is the difficulty of integrating costs and environmental impacts across logistics operations (Lai, Harjatib, McGinnisc, Zhouc \& Guldbergd, 2008).

Several studies that address this issue have focused their attention on packaging due to its importance in supply chain management (Albrecht, Brandstetter, Beck, Fullana-i-Palmer, Grönman, Baitz et al., 2013; Pires, Sargedas, Miguel, Pina \& Martinho, 2017; Verghese, Horne \& Carre, 2010). Under this scenario, García-Arca, Gonzalez-Portela-Garrido and Prado-Prado (2014; 2017) have developed the new concept of "Sustainable Packaging Logistics". This approach is based on the idea that packaging has to satisfy protection, commercial, logistics and environmental requirements from a sustainable perspective. This leads to conceive packaging as a strategic element related to the organization economic and environmental performances, which are key aspects in terms of sustainability.

A foremost intersection point between environmental and economic factors is the reverse flow in the supply chain, where packaging has a very important role (García-Arca et al., 2014; Lentes, Mandel, Schliessmann, Blach, Hertwig \& Kuhlmann, 2017; White, Wang \& Li, 2015). Consequently, many studies on sustainability have established comparisons among returnable and disposable packaging items (Albrecht et al., 2013; Atamer, Bakal \& Bayindir, 2013; Goudenege, Chu \& Jemai, 2013). On the one hand, Atamer et al., clarifies that in order to maximize manufacturer's profit, if there is no restriction on the production capacity, the manufacturer always utilizes returnable packaging, even if the returnable packaging unit costs more than a regular brand-new container. On the other hand, Goudenege et al., concludes that the use of reusable packaging is not always cheaper. According to these authors, if transport costs are high, the use of disposable packaging may be the best alternative economically-wise. Furthermore, Goudenege et al. found that transport emissions corresponding to packaging return are too substantial to represent environmental benefits compared to disposable packaging model. Nevertheless, other authors are skeptical about this assertion (Levi, Cortesi, Vezzoli \& Salvia, 2011; Woods \& Bakshi, 2014). The unclear conclusions about this topic have made some companies develop their own packaging strategies in order to reduce environmental impacts (Mazeika-Bilbao, Carrano, Hewitt \& Thorn, 2011). This disparity between the environmental and economic aspects of packaging utilization extends to the rest of the literature.

One of the main reasons for this disparity could be the difficulty in obtaining an indicator that allows the evaluation of economic and environmental aspects at the same time. Several studies have focused their attention on the KPI's (Key Performance Indicators) used by companies to evaluate how sustainable their businesses are (Bai \& Sarkis, 2014; Kylili, Fokaides \& Jimenez, 2016; Piecyk \& Björklund, 2015). Nevertheless, these studies have shown that companies use a wide range of KPI's to evaluate each one of the sustainability pillars, generating a long list of indicators that needs to be managed. This has led some authors to develop methodologies based on aggregating all the indicators into a unique index (Azevedo \& Barros, 2017; Erol, Sencer \& Sari, 2011; Pérez, Guerrero, González, Pérez \& Caballero, 2013). For example, Azevedo and Barros (2017) have designed a composite index giving a different weight to each one of the sustainability dimensions. However, this kind of composite indicators might not be intuitive to practitioners due to their academic perspective.

Few researchers have addressed the connection between economic and environmental sustainability from a more practical point of view, as might be the implementation of packaging alternatives in real companies and the evaluation of the outcomes. Therefore, a lack of case studies that provide transparent methodologies for evaluating the suitability of different packaging strategies along with conclusive results has been found. 
The aim of this paper is to compare the use of reusable boxes and disposable boxes in a real agro-food company, focusing on their environmental and economic impacts. The case study presented shows how environmental aspects are affected by cost reduction in distribution to customers. The allocation logic of a packaging system is optimized first by implementing the most cost-efficient type of packaging in each sales region. Finally, environmental implications are assessed on the basis of the company's initial situation.

\section{Research Methodology}

As a first step to achieve the above-stated research objectives, the authors performed a rigorous literature review on methodologies that show users how to evaluate the economic and environmental impacts of using disposable and reusable boxes. Several methodologies show how to determine the main packaging costs (Levi et al., 2011; Mollenkopf, Closs, Twede, Lee \& Burgess, 2005; Zhang, Segerstedt, Tsao \& Liu, 2015). Despite this, after reviewing 121 articles, Hochrein, Glock, Bogaschewsky and Heider (2015) indicated that the cost calculation methods vary significantly among researchers. Therefore, with the purpose of establishing the disposable and reusable boxes total cost, a simple methodology was applied in our study. First, our method separates process costs and transport costs. The process costs are the result of the unitary cost of different operations and manipulations imputed to each box, while the transport costs involve greater complexities. Transport costs imputed to each box, which are based on boxes' weight, are discussed in more detail in the case study section.

Calculating the environmental impact of a product requires more effort. In furtherance of this challenge, the Life Cycle Assessment (LCA) becomes a great starting point. This methodology shows users how to measure the environmental impact quantitatively, and it is based on the analysis of each stage of product cycle life: extraction of raw material, production, distribution, use and end of life. The next step consists on carrying out the Life Cycle Inventory (LCI) by determining inputs and outputs during the product cycle life, and then evaluating the environmental impacts (LCIA). Both analyses become highly complicated due to both the enormous variety of operational standards required and the data collection itself. Among the numerous organizations that have made efforts to standardize LCA, ISO (International Organization for Standardization) is the most widely recognized thanks to the ISO 14040 family. Other indicators that can be used are product footprints, such as the ecological footprint, the water footprint and the carbon footprint, being the last one the most popular. ISO has also published the ISO 14060 family, a large number of standards on how to calculate the carbon footprint. Both the LCA methodology and the carbon footprint are applied in our study, as ISO 14044:2006 (ISO, 2006a) and ISO 14064:2006 (ISO, 2006b) respectively indicate. When calculating the carbon footprint, the GEI emissions are measured in homogenous units $\left(\mathrm{kg} \mathrm{CO}_{2} \mathrm{eq}\right)$.

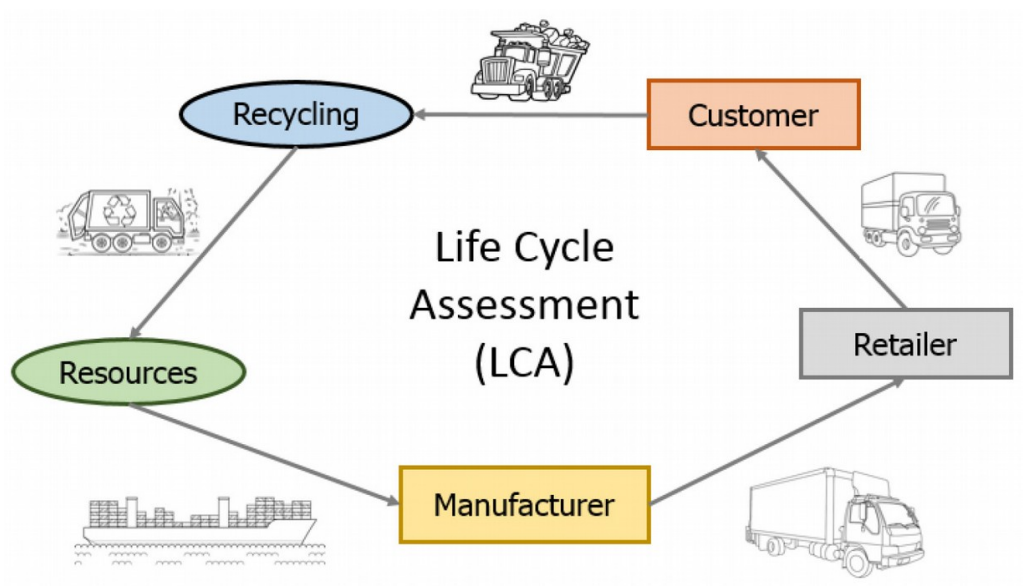

Figure 1. Life Cycle Assessment approach

When measuring economic and environmental impacts, a composite indicator can be used due to the existence of $\mathrm{CO}_{2}$ markets. These markets emerged as a result of the Kyoto Protocol and allow the trading of Carbon Credits, whose price rise and fall over time. This market allows to measure the economic impact of $\mathrm{CO}_{2}$ emissions and, 
consequently, to obtain a composite indicator in monetary terms. Thus, economic and environmental impacts could be evaluated through only one indicator. This technique has been used by some authors in order to perform previous studies on sustainability aspects (Dattilo, Delogu, Berzi \& Pierini, 2016; Köylüglu, 2016). However, today's price of $\mathrm{CO}_{2}$-ton in the European Market is too low to represent a considerable amount of money; $5.35 € /$ ton was the average value in 2016. Therefore, this indicator would not be sensitive to a variation in the environmental impact. According to these considerations, the measurements of the economic and environmental impacts are carried out separately.

Now, the case study presented is briefly introduced and then divided into two main sections: first, the economic and environmental analyses of the initial company's packaging strategy for distribution to customers, and second, the economic optimization of the system and the consequent impact of this optimization on the carbon footprint.

\section{Case Study}

The company chosen is a manufacturer and wholesaler of pork meat located in Galicia, Spain. The business belongs to an important Spanish agro-food group, composed of several factories. The company under study currently handles three references of products. In terms of packaging, the company also uses three formats of boxes: Box 1 (returnable plastic box), Box 2 (disposable cardboard box) and Box 3 (rented by a logistics service provider), being the first one and the last one made of the same material (HDP). The three boxes are able to carry any of the three references, but they have different load capacities depending on the reference carried. Table 1 summarizes this information, as well as the weight of each box.

\begin{tabular}{|l|r|r|r|r|}
\hline & Weight (kg) & $\begin{array}{c}\text { Load capacity } \\
\rightarrow \text { Ref. 1 (kg) }\end{array}$ & $\begin{array}{c}\text { Load capacity } \\
\rightarrow \text { Ref. 2 (kg) }\end{array}$ & $\begin{array}{l}\text { Load capacity } \\
\rightarrow \text { Ref. 3 (kg) }\end{array}$ \\
\hline Box 1 & 2 & 15 & 10 & 12 \\
\hline Box 2 & 0.635 & 13.5 & 9 & 10.8 \\
\hline Box 3 & 2.07 & 18 & 12 & 14.4 \\
\hline
\end{tabular}

Table 1. Packaging data

The company operates three different types of lorries depending on the geographic distribution of its customers in Spain. Customers located nearby are served with small lorries, which can be loaded up to 3.5 ton. To supply the rest of Galicia, the boxes are carried in a lorry with capacity up to 4.8 ton. An 11.5-ton lorry carries boxes to the rest of Spain.

\subsection{The Current Packaging Strategy. The Box Selection Process}

The box selection process is done according to the location of customers. The company mainly develops its activity in Galicia, therefore returnable plastic boxes (Box 1) are used in this case. If the customer is located outside Galicia, the company assumes that managing reverse logistics is too difficult, and that it implies high losses. Thus, the company has made the decision of using cardboard boxes (Box 2) to serve non-Galician companies. However, some customers (located in large areas) specifically require the use of boxes from certain providers of logistics services such as Euro Pool (Box 3), which rents the buckets and collects them later from the customer's factory. In order to obtain the costs of distributing when using each of the three different boxes (shown in Table 2), process costs had to be allocated, including costs of acquisition (renting for Box 3), handling, washing, assembling and maintenance. For Box 1, the acquisition cost was divided by the estimated number of uses during its lifetime, in order to calculate the acquisition cost corresponding to each cycle.

As well as process costs, transport to customers and reverse logistics expenses were considered, being the latter only applicable for Box 1. Transport costs were calculated based on the cost per $\mathrm{km}$ for each modality of road transport (information provided by ACOTRAM, a software property of the Spanish Ministry of Development) and boxes weight. Lorries and boxes load capacities varied depending on the product carried, which was also taken into 
account. To calculate the distance traveled in each distribution process, the demand was aggregated by province. The distance considered is the one between the company and the province capital in any case. Google Maps was the software used in this process.

\begin{tabular}{|c|c|c|c|}
\hline & Box 1 & Box 2 & Box 3 \\
\hline Acquisition/Rental & $0.10 €^{*}$ & $0.55 €$ & $0.69 €$ \\
\hline Handling & $0.01 €$ & $0.03 €$ & $0.03 €$ \\
\hline Maintenance & $0.06 €$ & - & - \\
\hline Washing & $0.04 €$ & - & - \\
\hline Assembly & - & $0.03 €$ & $0.02 \mathrm{e}$ \\
\hline Total & $0.21 €$ & $0.61 €$ & $0.74 €$ \\
\hline
\end{tabular}

$*$ An average of 38 uses was considered (Acquisition cost $=3.65 €$ )

Table 2. Process costs for each type of box

Then, carbon footprint was calculated according to ISO 14044:2006 (ISO, 2006a) and ISO 14064:2006 (ISO, 2006b). Each box lifecycle stage was identified and analyzed, and finally the emissions level was obtained given in $\mathrm{kg}$ $\mathrm{CO}_{2}$ eq. In furtherance of determining the emissions values, some conversion factors were applied (ASIPLA, 2011; IVL, 2010; OCCC, 2015). Consequently, it was possible to estimate $\mathrm{CO}_{2}$ eq emissions using a 1-ton demand-base for each product reference. Table 3 shows these values, excluding those related to transport to client's plant and packaging return activities, which are described hereunder.

\begin{tabular}{|l|r|r|r|}
\hline & Ref. 1 & Ref. 2 & Ref. 3 \\
\hline Box 1 & 12.99 & 19.48 & 16.23 \\
\hline Box 2 & 49.17 & 73.75 & 61.46 \\
\hline Box 3 & 4.68 & 7.03 & 5.85 \\
\hline
\end{tabular}

Table 3. Emissions corresponding to $1000 \mathrm{~kg}$ demand ( $\mathrm{kg} \mathrm{CO} / 1000 \mathrm{~kg}$ ref.)

In a similar way to the cost analysis and whit the purpose of determining the emissions level of transport to customers and packaging return processes, it was needed to contemplate boxes weight and capacity, lorries load capacity and the distance travelled by lorries during the distribution process. The demand was also aggregated by province. For Box 3, the estimated distance for the packaging return was the one between the province capital where the customer is located and Madrid, where the logistics services provider is placed.

Finally, by including sales information of one year of observation (2015), the global cost and the global carbon footprint attributable to the company's packaging strategy were obtained. The cost and the carbon footprint amounted to $932,676 €$ and $809,247 \mathrm{~kg} \mathrm{CO}$ eq respectively.

\subsection{A More Sustainable Box Selection Process}

Aiming to improve the current packaging strategy in terms of cost reduction, the box selection process was redesigned. In the optimized model, the use of Box 1 was found to be cheaper for provinces that made more than 20 orders per year. In the rest of provinces, the box sent is either Box 2 or Box 3, depending on which one is cheaper. In this optimized box selection model, no trade-related agreement was taken into consideration. This new decision criteria ensures that that the company's reusable boxes are under control, since we assumed the more frequent the shipments, the easier to control the boxes. The final geographic allocation logic for the boxes, purely based on the economic criteria, can be observed in Figure 2. 


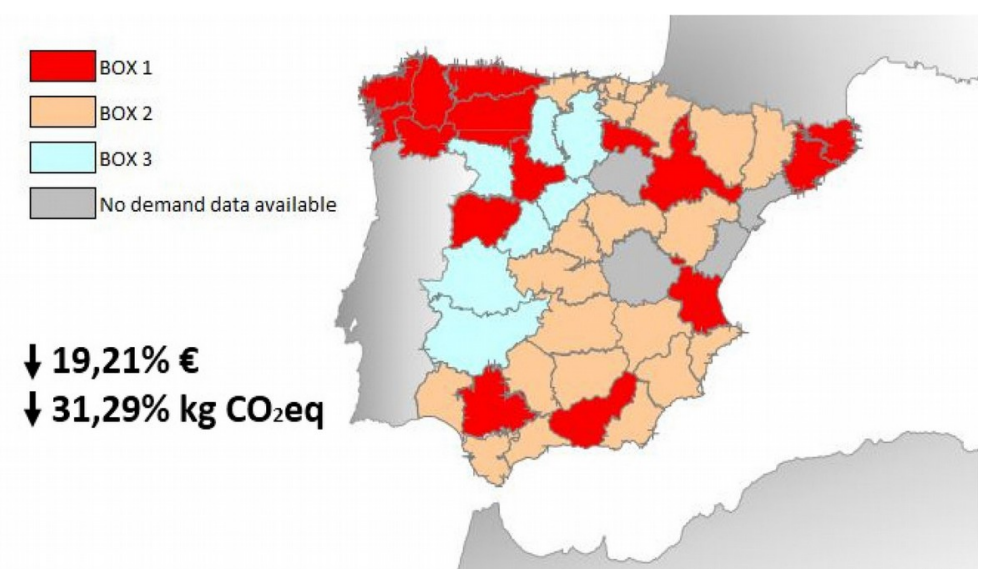

Figure 2. Final allocation logic by provinces

As depicted in the picture, the number of provinces using the returnable plastic box, Box 1, increased from 4 to 15 provinces (91.12\% of the 2015 demand). However, the number of provinces where Box 2, the disposable box, should be sent decreased from 39 to 21 (6.24\%\% of the 2015 demand). Box 3, which in the starting situation was only considered in cases of trading-related agreements, was found as the most appropriate in 7 provinces $(2.64 \%$ of the 2015 demand). The carbon footprint calculations of the final box selection model were the same as the ones used to evaluate the starting situation. To validate the goodness of this new box packaging strategy, the aggregate results of total cost and carbon footprint were measured. Both amounted, respectively, to 753,541 € and 556,319 $\mathrm{kg}$ $\mathrm{CO}_{2}$ eq.

Finally, the results can be discerned. On the one hand, the new box assignment logic would reduce the total cost by almost $20 \%$, which represents $179,135 €$ in terms of absolute value. On the other hand, by using the new selection process the carbon footprint would also be reduced by $252,928 \mathrm{~kg} \mathrm{CO}_{2}$ eq, more than $31 \%$ of the original level.

\section{Discussion and Further Research}

The results obtained in this case study show the viability of a win-win relationship that several researchers (Atilgan \& Azapagic, 2016; Battini, Calzavara, Persona \& Sgarbossa, 2016; Carter \& Rogers, 2008; Cordero, 2013; Garza-Reyes, Villarreal, Kumar \& Molina-Ruiz, 2016) have found in the past. According to this approach, adopting environmentally sustainable policies may have a positive impact on cost reduction. Carter and Rogers (2008) highlighted that it is especially important that one of the dimensions favored by this win-win relationship is the economic one, since it makes it more likely that companies adopt sustainable best practices. Initiatives in the environmental pillar are clearly desirable, but they could be hard to implement if the economic pillar is not benefited too.

Despite the notoriety of the win-win relationship in this case study, it is noteworthy that results may vary significantly depending on the values of the input data. This is critical when developing the packaging strategy of a company (Battini et al., 2016). For example, in the case analyzed by the authors, the corrugated cardboard box is clearly the best alternative in all cases, even when different scenarios are considered. Thus, it is not possible to establish a general rule for identifying the most suitable alternative of packaging, but it is necessary to study each case to determine it. In certain situations, there could even be a limit for the multi-pillar improvement, being necessary to establish priorities between them. However, this issue only happens in companies highly experienced in implementing sustainability practices. Detecting win-win opportunities becomes a great starting point for companies in order to align external stakeholders' and companies' interests.

Delving into the importance of input values, the authors are aware that the allocation logic for boxes obtained in this case study could have been quite different. Looking at Figure 2, it is true that most provinces furthest from the starting point are served using Box 2. However, if the threshold at which using Box 2 is cheaper than using Box 3 decreased, the total value of the carbon footprint would increase. Likewise, the results obtained could be enhanced 
if the company improved its own reusable boxes management (Box 1) and increased the number of uses during its lifetime.

Besides, it is noteworthy the high difficulty of identifying coherent conversion factors in literature for evaluating the environmental impact of the packaging strategy of the company. This is due to the existence of many different emission factors related to each process. In addition, Cordero (2013) remarked that literature is scarce regarding methodologies for carbon footprint calculation in several models of supply chain. Both facts lead to obtain different conclusions depending on the sources consulted and the methodologies applied when evaluating the environmental impact of packaging strategies. Further research should focus their effort on giving consistency to these conversion factors and developing a model to easily measure carbon footprint in different scenarios. Finally, we would like to stress the need for a composite and intuitive indicator that allowed practitioners to evaluate more than a sustainability aspect simultaneously.

Since, in our particular case, the weight of the lorries was considered to be the only restrictive variable when carrying goods, one limitation of our calculation model is the lack of volumetric limitations, which could also be a great starting point for future research. Box 1 and Box 3 have some characteristics that facilitate their handling and even allow their folding in case of reverse flows. Thus, it could be interesting to incorporate the volume carried as a new variable, in order to better calculate the impact of reverse logistics in terms of cost and environmental impact. Additionally, future work could apply the same methodology to other companies that have similar packaging strategies and see if the results obtained are in agreement with our work and if economic and environmental win-win situations are more likely to happen.

\section{Conclusions}

In this case study, economic and environmental aspects were taken into account in order to measure the goodness of the packaging strategy of an agro-food company. The company uses different types of boxes for distributing its products, including disposable cardboard boxes and returnable plastic boxes managed by the company or by a third-party logistics. The results have shown that by designing a more sustainable model for boxes allocation, both the economic and the environmental impacts attributable to the packaging strategy can be reduced. In our particular case, the total costs were reduced by almost $20 \%$, while the carbon footprint decreased over $31 \%$, which confirms the striking relationship between both aspects.

In today's increasingly competitive market, finding win-win relationships that satisfy stakeholders' wishes and improve companies' performances is the key to success. In this context, we think it is of significant interest to combine waste elimination practices (such as "Lean Management") with sustainable initiatives. Several case studies (Atilgan \& Azapagic, 2016; Battini et al., 2016; Garza-Reyes et al., 2016), including ours, have proved that connecting both worlds is possible.

Finally, these implications are highly related to the growing social and govern-mental pressures that companies suffered asking them to minimize their environmental impact. Therefore, organizations should follow this current trend and try to find a formula to decrease both the economic and the environmental impacts of their packaging strategies. This fact enhances the value of our work and shows an important line of research, with the aim of analyzing how and to what extent both aspects can go hand in hand.

\section{Declaration of Conflicting Interests}

The authors declared no potential conflicts of interest with respect to the research, authorship, and/or publication of this article.

\section{Funding}

The authors received no financial support for the research, authorship, and/or publication of this article. 


\section{References}

Albrecht, S., Brandstetter, P., Beck, T., Fullana-i-Palmer, P., Grönman, K., Baitz, M. et al. (2013). An extended life cycle analysis of packaging systems for fruit and vegetable transport in Europe. The International Journal of Life Cycle Assessment, 18(8), 1549-1567. https://doi.org/10.1007/s11367-013-0590-4

ASIPLA (Asociación Gremial de Industriales del Plástico de Chile) (2011). Análisis del impacto de los gases de efecto invernadero en el ciclo de vida de los embalajes y otros productos plásticos en Chile V1.0. Accessed February 2017 from: http://www.acoplasticos.org/boletines/2011/Noticias Ambientales 2011 04Julio/ASIPLA Huella de Carbono.pdf

Atamer, B., Bakal, I., \& Bayindir, Z. (2013). Optimal pricing and production decisions in utilizing reusable containers. International Journal of Production Economics, 143(2), 222-232. https://doi.org/10.1016/j.ijpe.2011.08.007

Atilgan, B., \& Azapagic, A. (2016). An integrated life cycle sustainability assessment of electricity generation in Turkey. Energy Policy, 93, 168-186. https://doi.org/10.1016/j.enpol.2016.02.055

Azevedo, S., \& Barros, M. (2017). The application of the triple bottom line approach to sustainability assessment: The case study of the UK automotive supply chain. Journal of Industrial Engineering and Management, 10(2), 286. https://doi.org/10.3926/jiem.1996

Bai, C., \& Sarkis, J. (2014). Determining and applying sustainable supplier key performance indicators. Supply Chain Management: An International Journal, 19(3), 275-291. https://doi.org/10.1108/SCM-12-2013-0441

Battini, D., Calzavara, M., Persona, A., \& Sgarbossa, F. (2016). Sustainable packaging development for fresh food supply chains. Packaging Technology and Science, 29(1), 25-43. https://doi.org/10.1002/pts.2185

Bendul, J., Rosca, E., \& Pivovarova, D. (2017). Sustainable supply chain models for base of the pyramid. Journal of Cleaner Production, 162, S107-S120. https://doi.org/10.1016/j.jclepro.2016.11.001

Carter, C.R., \& Rogers, D.S. (2008). A framework of sustainable supply chain management: moving toward new theory. International Journal of Physical Distribution \& Logistics Management, 38(5), 360-387. https://doi.org/10.1108/09600030810882816

Cordero, P. (2013). Carbon footprint estimation for a sustainable improvement of supply chains: state of the art. Journal of Industrial Engineering and Management, 6(3), 805. https://doi.org/10.3926/jiem.570

Dattilo, C.A., Delogu, M., Berzi, L., \& Pierini, M. (2016). A sustainability analysis for Electric Vehicles Batteries including ageing phenomena. In Environment and Electrical Engineering (EEEIC), IEEE 16th International Conference on (1-6). https://doi.org/10.1109/EEEIC.2016.7555836

Elkington, J. (1997). Cannibals with forks: The triple bottom line of the 21st century. Capstone

Erol, I., Sencer, S., \& Sari, R. (2011). A new fuzzy multi-criteria framework for measuring sustainability performance of a supply chain. Ecological Economics, 70(6), 1088-1100. https://doi.org/10.1016/j.ecolecon.2011.01.001

García-Arca, J., González-Portela-Garrido, A.T., \& Prado-Prado, J.C. (2017). "Sustainable Packaging Logistics”. The link between Sustainability and Competitiveness in Supply Chains. Sustainability, 9(7), 1098.

https://doi.org/10.3390/su9071098

García-Arca, J., Gonzalez-Portela-Garrido, A.T., \& Prado-Prado, J.C. (2014). "Packaging logistics": Promoting sustainable efficiency in supply chains. International Journal of Physical Distribution \& Logistics Management, 44(4), 325-346. https://doi.org/10.1108/IJPDLM-05-2013-0112

Garza-Reyes, J.A., Villarreal, B., Kumar, V., \& Molina-Ruiz, P. (2016). Lean and green in the transport and logistics sector - A case study of simultaneous deployment. Production Planning \& Control, 27(15), 1221-1232. https://doi.org/10.1080/09537287.2016.1197436 
Goudenege, G., Chu, C., \& Jemai, Z. (2013). Reusable containers management: from a generic model to an industrial case study. Supply Chain Forum: An International Journal, 38(4), 26-38.

https://doi.org/10.1080/16258312.2013.11517313

Hochrein, S., Glock, C.H., Bogaschewsky, R., \& Heider, M. (2015). Literature reviews in supply chain management: a tertiary study. Management Review Quarterly, 65(4), 239-280. https://doi.org/10.1007/s11301-015-0113-4

ISO (International Organization for Standardization) (2006a). ISO 14044: Environmental management - Life cycle assessment - Requirements and guidelines. Geneva, Switzerland.

ISO (International Organization for Standardization) (2006b). ISO 14064: Greenhouse gases - Parts 1, 2 \& 3. Geneva, Switzerland.

IVL (Swedish Environmental Research Institute) (2010). Carbon footprint of cartons in Europe - Carbon footprint methodology and biogenic carbon sequestration. http://www.ivl.se/download/18.343dc99d14e8bb0f58b75c7/1445517446481/B1924.pdf (Accessed: February 2017).

Johansson, O., \& Hellström, D. (2007). The effect of asset visibility on managing returnable transport items. International Journal of Physical Distribution \& Logistics Management, 37(10), 799-815.

https://doi.org/10.1108/09600030710848923

Köylüglu, O. (2016). Tendering based on life cycle cost and life cycle analysis. ABSE Congress Stockholm, 2016: Challenges in Design and Construction of an Innovative and Sustainable Built Environment (677-684).

Kylili, A., Fokaides, P.A., \& Jimenez, P.A.L. (2016). Key Performance Indicators (KPIs) approach in buildings renovation for the sustainability of the built environment: A review. Renewable and Sustainable Energy Reviens, 56, 906-915. https://doi.org/10.1016/j.rser.2015.11.096

Lai, J., Harjatib, A., McGinnisc, L., Zhouc, C., \& Guldbergd, T. (2008). An economic and environmental framework for analyzing globally sourced auto parts packaging system. Journal of Cleaner Production, 16(5), 1632-1646. https://doi.org/10.1016/j.jclepro.2008.01.011

Lentes, J., Mandel, J., Schliessmann, U., Blach, R., Hertwig, M., \& Kuhlmann, T. (2017). Competitive and sustainable manufacturing by means of ultra-efficient factories in urban surroundings. International Journal of Production Research, 55(2), 480-491. https://doi.org/10.1080/00207543.2016.1189106

Levi, M., Cortesi, S., Vezzoli, C., \& Salvia, G. (2011). A comparative life cycle assessment of disposable and reusable packaging for the distribution of Italian fruit and vegetables. Packaging Technology and Science, 24(7), 387-400. https://doi.org/10.1002/pts.946

Mazeika-Bilbao, A., Carrano, A.L., Hewitt, M., \& Thorn, B.K. (2011). On the environmental impacts of pallet management operations. Management Research Review, 34(11), 1222-1236. https://doi.org/10.1108/01409171111178765

Mollenkopf, D., Closs, D., Twede, D., Lee, S., \& Burgess, G. (2005). Assessing the viability of reusable packaging: A relative cost approach. Journal of Business Logistics, 26(1), 169-197. https://doi.org/10.1002/j.2158-1592.2005.tb00198.x

OCCC (Oficina Catalana de Camvi Climàtic) (2015). Guia pràctica per al càlcul d'emissions de gasos amb efecte d'bivernacle (GEH). http://canviclimatic.gencat.cat/web/.content/home/campanyes i comunicacio/publicacions/publicacions de canvi climatic/ Guies calcul emissions GEH/150301 Guia-practica-calcul-emissions sense-canvis CA v2.pdf (Accessed: February 2017)

Pérez, V., Guerrero, F., González, M., Pérez, F., \& Caballero, R. (2013). Composite indicator for the assessment of sustainability: The case of Cuban nature-based tourism destinations. Ecological Indicators, 29, 316-324.

https://doi.org/10.1016/j.ecolind.2012.12.027

Piotrowicz, W., \& Cuthbertson, R. (2015). Performance measurement and metrics in supply chains: An exploratory study. International Journal of Productivity and Performance Management, 64(8), 1068-1091.

https://doi.org/10.1108/IJPPM-04-2014-0064 
Piecyk, M.I., \& Björklund, M. (2015). Logistics service providers and corporate social responsibility: sustainability reporting in the logistics industry. International Journal of Physical Distribution \& Logistics Management, 45(5), 459-485. https://doi.org/10.1108/IJPDLM-08-2013-0228

Pires, A., Sargedas, J., Miguel, M., Pina, J., \& Martinho, G. (2017). A case study of packaging waste collection systems in Portugal-Part II: Environmental and economic analysis. Waste Management, 61, 108-116. https://doi.org/10.1016/j.wasman.2016.11.032

Verghese, K.L., Horne, R., \& Carre, A. (2010). PIQET: the design and development of an online 'streamlined' LCA tool for sustainable packaging design decision support. The International Journal of Life Cycle Assessment, 15(6), 608-620. https://doi.org/10.1007/s11367-010-0193-2

White, G.R., Wang, X., \& Li, D. (2015). Inter-organisational green packaging design: a case study of influencing factors and constraints in the automotive supply chain. International Journal of Production Research, 53(21), 6551-6566. https://doi.org/10.1080/00207543.2014.975854

Woods, L., \& Bakshi, B.R. (2014). Reusable vs. disposable cups revisited: guidance in life cycle comparisons ad-dressing scenario, model, and parameter uncertainties for the US consumer. The International Journal of Life Cycle Assessment, 19(4), 931-940. https://doi.org/10.1007/s11367-013-0697-7

World Commission on Environment and Development (1987). Our common future. New York, NY: Oxford University Press.

Zhang, Q., Segerstedt, A., Tsao, Y.C., \& Liu, B. (2015). Returnable packaging management in automotive parts logistics: Dedicated mode and shared mode. International Journal of Production Economic, 168, 234-244.

https://doi.org/10.1016/j.ijpe.2015.07.002

Journal of Industrial Engineering and Management, 2018 (www.jiem.org)

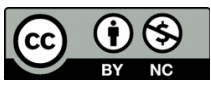

Article's contents are provided on an Attribution-Non Commercial 4.0 Creative commons International License. Readers are allowed to copy, distribute and communicate article's contents, provided the author's and Journal of Industrial Engineering and Management's names are included. It must not be used for commercial purposes. To see the complete license contents, please visit https://creativecommons.org/licenses/by-nc/4.0/. 